\title{
Crenças e ações dos discentes quanto ao desenvolvimento da habilidade de produção oral durante aulas online na pandemia da COVID-19
}

\author{
Students' beliefs and actions regarding the development of oral production skill during online classes in the
}

COVID-19 pandemic

\section{Mônica Bezerra da Silva Fernandes}

Secretaria da Educação do Distrito Federral - SEDF - Distrito Federal - Brasil

\section{Yûki Mukai}

Universidade de Brasília - UnB - Distrito Federal - Brasil

\begin{abstract}
Resumo: O presente trabalho tem como objetivo investigar as crenças e ações dos discentes quanto ao próprio desenvolvimento da produção oral em aulas online de um curso livre de inglês como língua estrangeira. A seção teórica baseia-se em: Barcelos (2001, 2006, 2010, 2011), Pajares (1992), Dewey (1933), Kalaja (1995), Riley (1997), Mukai (2014), para discorrer sobre crenças; Ur (1996), Santos e Barcelos (2018), Gonzáles (2008), Oxford (1990), Marcuschi (2010), Feijó e Mukai (2014), sobre oralidade; e Martins e Mill (2016), Santos (2011), Paiva (2018) e Aragão, Paiva e Junior (2017), acerca de aulas online. Para tanto, foi realizada uma pesquisa qualitativa interpretativista engajada em um estudo de caso coletivo (STAKE, 2005) com base na abordagem contextual para estudos de crenças (BARCELOS, 2001). A pesquisa foi desenvolvida com cinco alunos adultos no primeiro semestre de 2020. Os discentes, em face da pandemia da COVID-19, não tiveram outra opção, senão aderir às aulas online para dar continuidade aos estudos. Os dados que foram analisados tiveram como instrumentos de coleta a observação não participante com notas de campo, o questionário, a narrativa escrita e a entrevista semiestruturada. Já os resultados desta pesquisa revelaram que, apesar de os participantes perceberem melhora na desenvoltura da produção oral durante as aulas online, o rendimento dos mesmos foi inferior às expectativas quando comparado às aulas presenciais. Eles creem que, ao realizarem determinadas ações, terão possibilidades maiores de evoluir na produção oral durante as aulas remotas.
\end{abstract}

Palavras-chave: Crenças e ações. Produção oral. Aulas online. Língua inglesa. COVID-19.

\begin{abstract}
This paper aims to investigate the beliefs and actions of students regarding the development of oral production in online classes of a free course in English as a foreign language (LE). In this sense, the theoretical section is based on: Barcelos (2001, 2006, 2010, 2011), Pajares (1992), Dewey (1933), Kalaja (1995), Riley (1997), Mukai (2014) to discuss about beliefs; Ur (1996), Santos \& Barcelos (2018), Gonzáles (2008), Oxford (1990), Marcuschi (2010), Mukai (2014), on orality; and Martins \& Mill (2016), Santos (2011), Paiva (2018), and Aragon, Paiva \& Junior (2017), about online classes. To this end, a qualitative-interpretative research engaged in a collective case study (STAKE, 1990) and based on the contextual approach to studies of beliefs (BARCELOS, 2001) was conducted. The research was developed with five adult students in the first semester of 2020. The students, in the face of the COVID-19 pandemic, had no other option but to join online classes to continue their studies. The data that were analyzed had as collection instruments a non-participant observation with field notes, a written narrative and a semi-structured interview. The results of this research revealed that, although participants perceive an improvement of the oral production during online classes, their performance was lower than expectations when compared to face-to-face classes. They believe that when carrying out certain actions, they will have a greater chance of evolving in oral production during remote classes.
\end{abstract}

Keywords: Beliefs and actions. Oral production. Online classes. English language. COVID-19. 


\section{INTRODUÇÃO}

A pandemia da COVID-19 acabou por paralisar totalmente as aulas presenciais em março de 2020 no Brasil em face da urgente necessidade de isolamento social. Com a finalidade de não interromper o ciclo pedagógico, alguns cursos livres de línguas optaram por realizar as aulas online.

Aprender uma língua estrangeira e, principalmente, ser capaz de se comunicar nessa língua, nos mais diversos contextos, é um desafio. No entanto, por conta da pandemia da COVID-19, a aprendizagem de uma língua estrangeira ficou ainda mais complexa para alunos, principalmente no que se refere ao desenvolvimento da habilidade de produção oral . Isso porque, caso a escola não proporcione aos alunos as aulas síncronas de forma remota, eles não poderão ter uma interação face a face nem de forma virtual. Almeida Filho (2011) enfatiza que, ao se experienciar a língua-alvo intensamente, maiores são as chances de que os aprendizes adquiram a capacidade de interagirem usando a língua.

No contexto de escolas de idiomas, universo de estudo utilizado nesta pesquisa, a produção oral assume grande relevância, já que os estudantes almejam se comunicar oralmente na língua inglesa. De fato, muitos indivíduos veem nesse aprendizado uma oportunidade para encontrar um bom emprego, ascender profissionalmente, realizar viagens internacionais, se conectar com outras pessoas ao redor do mundo, etc. Nesses contextos, é difícil alguém pensar em outras habilidades linguísticas, tais como a leitura e a escrita. Ou seja, podemos conceber que a maioria de alunos vêm para a escola de idiomas para adquirir a habilidade de produção oral (MUKAl, 2011; VASCONCELLOS, 2020).

No que se refere à aquisição da habilidade de produção oral, precisa-se do conhecimento sociolinguístico, além do gramatical. É a capacidade de usar a língua para transmitir e compreender mensagens, negociando significados entre as pessoas, dentro de contextos específicos (HYMES, 1971). Para Almeida Filho (2011, p. 56), a competência comunicativa é a "capacidade de mobilizar e articular conhecimento de língua e de comunicação, sob certas atitudes, e interação, com o propósito de se situar socialmente numa língua". Assim, percebe-se que, na habilidade em questão, estão envolvidos diversos fatores, tais como: o conhecimento gramatical e sociolinguístico, negociação de significados, interação, atitudes e intenção do falante, entre outros.

Dentro desse contexto, surgiram-nos alguns questionamentos relacionados ao desenvolvimento da habilidade de produção oral. Na sala de aula online, até que ponto os alunos conseguem desenvolver a referida habilidade na qual se envolvem os fatores acima mencionados? Como os alunos, que tiveram somente as aulas presenciais antes da pandemia da COVID-19, estão se sentindo e experienciando no que se refere ao seu próprio aprendizado, principalmente, ao desenvolvimento da habilidade de produção oral no novo ambiente virtual?

Para buscar desenvolver a produção oral, não basta assistir literalmente às aulas, sejam presenciais, sejam virtuais, mas os alunos precisam, além de interagir com o professor e colegas e negociar o significado, se verem como seres ativos e autônomos no processo de ensino-aprendizagem e também perceber como suas crenças e ações podem influir de forma negativa ou positiva nesse desenvolvimento. Kalaja et al. (2016) enfatizam que as crenças, entre muitos outros fatores, podem ter influência nos resultados da aprendizagem dos alunos.

Em virtude dessa circunstância, o presente trabalho foi realizado com um grupo de alunos que estavam cursando o terceiro semestre num curso livre de inglês, onde as aulas passaram a acontecer de forma remota a partir de abril de 2020, tendo como guia do estudo três indagações: (1) Quais as crenças dos alunos de língua inglesa quanto ao próprio desenvolvimento da habilidade de produção oral em aulas online?; (2) Que ações os alunos utilizam para desenvolver a oralidade na língua inglesa durante as aulas online?; (3) Qual a relação entre as crenças e ações dos alunos de língua inglesa quanto ao próprio desenvolvimento da produção oral em aulas online?.

Diante do exposto, acreditamos ser relevante 0 presente estudo cujo objetivo é identificar as crenças e ações dos discentes quanto ao próprio desenvolvimento da produção oral, em aulas online, 
em um curso livre de inglês como língua estrangeira (LE).

\section{Fundamentação teórica}

\subsection{Crenças e ações}

Segundo Pajares (1992), definir o que vem a ser crenças é algo complexo e investigá-las não é tarefa simples. Não existe um conceito fechado sobre as mesmas e com o avanço dos estudos sobre crenças, nota-se uma visão diferenciada destas, que passam a ser vistas como dinâmicas, dizendo respeito às nossas experiências, ao contexto em que estamos inseridos e estando também relacionadas a outros aspectos, como é descrito por Barcelos (2011) na definição a seguir:

Crenças não são somente um conceito cognitivo, mas também social, porque nascem de nossas experiências e problemas de nossa interação com o contexto e de nossa capacidade de refletir e pensar sobre o que nos cerca. As crenças são dinâmicas, paradoxais e complexas (BARCELOS, 2011, p. 301).

Dewey (1933) por sua vez, entende que

[Crença] abrange todas as matérias de que não temos conhecimento seguro, mas em que confiamos o bastante para nelas basear a nossa ação; e igualmente, as matérias aceitas como verdadeiras, como conhecimento, suscetíveis, todavia de futuras indagações (DEWEY, 1933, p. 6, tradução de Campos, 1959, p. 16).

Ao mencionar que as crenças são suscetíveis a mudanças, Dewey (1933), já infere que estas são variáveis e dinâmicas. Nesse sentido, o autor destaca a relação entre crenças e ações ao enfatizar que podemos basear nosso agir nas crenças que possuímos. Barcelos (2001, p. 83) também afirma que "crenças são vistas como específicas do contexto, ou seja, as crenças devem ser investigadas dentro do contexto de suas ações". Convergindo com a fala de Dewey (1933) e Barcelos (2001), Kalaja (1995) salienta que as crenças podem variar tanto de aluno para aluno, como de contexto para contexto, influindo diretamente no aprendizado de uma língua.

Barcelos (2001) frisa que as crenças influenciam o agir dos indivíduos e pode ter relação com as crenças que estes possuem. Nesta mesma perspectiva, Riley (1997 apud BARCELOS, 2001, p. 73) afirma que as crenças dos discentes em relação à aprendizagem de línguas podem influir na motivação, atitudes e estratégias que esses utilizam. Ainda, Mukai (2011) salienta que, por mais que o professor conheça técnicas para ensinar, o ensino de língua estrangeira pode não ter sucesso se seu ponto de vista e o do aluno divergem muito. Assim, conhecer as crenças dos discentes e como essas podem interferir nas ações dos mesmos e vice-versa pode levar a uma reflexão acerca das atividades orais propostas durante as aulas online, gerando assim, talvez, aulas mais produtivas com esse propósito.

\subsection{Produção Oral}

Para várias pessoas que decidem estudar uma língua estrangeira, ser capaz de se comunicar nesta língua é uma meta nem sempre fácil de ser atingida. Ur (1996, p. 120 apud SANTOS; BARCELOS, 2018, p. 17) enfatiza que "de todas as quatro habilidades (compreensão oral, produção oral, leitura e escrita), a produção oral parece intuitivamente a mais relevante: as pessoas que sabem uma língua são referidas como 'falantes' dessa língua”. Conforme elucida Gonzáles (2008), vários fatores podem interferir na capacidade de se expressar oralmente. O autor salienta que, além de o falante precisar pensar acerca do que e do como dizer, em um curto espaço de tempo, o seu conhecimento de língua estrangeira pode influenciar no uso adequado da mesma nas diversas situações de comunicação.

Em se tratando de situações de comunicação, Oxford (1990) afirma que, para desenvolver a competência de se comunicar, é preciso que haja interação real entre os estudantes a partir do uso de linguagem significativa e contextualizada. Falar bem uma língua significa ser capaz de usar esta língua de forma a gerar interação nos mais diversos contextos sociais, sejam eles formais ou não. Assim sendo, procurar desenvolver atividades que levem os alunos ao desenvolvimento da produção oral precisa ser uma constante nas aulas. Conforme destaca Marcuschi 
(2010, p. 25), “a oralidade seria uma prática social interativa para fins comunicativos que se apresenta sob variadas formas ou gêneros textuais fundados na realidade sonora; ela vai desde uma realização mais informal à mais formal nos mais variados contextos de uso".

De acordo com Feijó e Mukai (2014), a habilidade de produção oral é uma competência na qual os estudantes expõem suas ideias e pensamentos para se comunicar com seu interlocutor ou audiência. Para que a comunicação ocorra, esses selecionam expressões, formas gramaticais e vocabulário para serem utilizados num determinado contexto. Em consonância com o conceito acima descrito, buscamos identificar as crenças e ações dos alunos no que diz respeito a essa capacidade de se comunicar com seus pares durante as aulas online.

\subsection{Aulas Online}

As aulas online propiciam aos alunos, que por diversas razões não podem realizar o curso de forma presencial, uma oportunidade de darem continuidade aos estudos. Quanto à finalidade da educação a distância, Martins e Mill (2016, p. 122) revelam que "ela foi criada com a intenção de promover o ensino e a formação continuada, almejando a democratização e o acesso ao conhecimento para todos, em todos os lugares".

No entanto, segundo Santos (2011), somente a inserção de tecnologias na educação não será suficiente na criação e manutenção de processos de inteligência coletiva, já que a sala de aula virtual precisa incrementar momentos de troca entre aqueles que dela participam. O mesmo autor destaca, ainda, não ser fácil perceber procedimentos pedagógicos adequados no ambiente de educação que é proporcionado através da sala de aula virtual, onde as tecnologias são apenas ferramentas imóveis cujo funcionamento é dependente do agir do professor (SANTOS, 2011).

Comungando da mesma visão, Paiva (2018) afirma que as tecnologias, ao serem utilizadas, servem de apoio ao desenvolvimento das habilidades orais, entretanto, destaca ser importante que momentos de interação síncrona ocorram e propõe, por exemplo, a utilização do aplicativo skype. Com base em seus estudos, a autora ressalta que a utilização das ferramentas não proporcionou experiências de conversação como as que acontecem face a face nas aulas presenciais, acrescentando, porém, que as ferramentas podem contribuir para criar mais oportunidades de prática da língua, além de reduzir a ansiedade.

Ainda, num outro estudo, desenvolvido por Aragão, Paiva e Junior (2017), ficou evidente que as ferramentas digitais podem colaborar com a aprendizagem ao proporcionar, além de momentos de prática frequentes e continuados, um ambiente onde a inibição, vergonha e medo de se expor oralmente sejam atenuados ou não existam. Desse modo, podese considerar que as aulas online devem promover momentos de prática oral que podem ser incrementados através do uso das mais diversas ferramentas, mas que estes não substituem os momentos de interação e prática que ocorrem durante as aulas presenciais (PAIVA, 2018).

\section{Metodologia}

\subsection{Método e natureza da pesquisa}

A presente pesquisa tem como método a pesquisa qualitativa (FLICK, 2007) de caráter interpretativista (BORTONI-RICARDO, 2008), além de ser um estudo de caso coletivo (STAKE, 2005), já que o que se pretende retratar são as crenças e ações de um grupo de alunos quanto ao seu próprio desenvolvimento oral, durante as aulas online, em tempos de pandemia da COVID-19.

Para a investigação de crenças, teremos como base a abordagem contextual de Barcelos (2001), que busca investigar as crenças a partir da observação dos indivíduos atuando no contexto onde as mesmas acontecem.

\subsection{Contexto da pesquisa e participantes}


A pesquisa foi realizada num curso livre de idiomas de Brasília (DF) onde são oferecidos cursos de francês, espanhol, japonês e inglês. O curso de inglês completo, tendo início no nível (Básico 1), tem a duração de seis anos, perfazendo um total de 12 semestres. O grupo de alunos observado de forma não participante estava cursando o terceiro semestre de inglês (Básico 3), sendo todos adultos. Embora a turma tivesse sete alunos que frequentavam as aulas com certa regularidade, cinco alunos se dispuseram a participar do presente estudo.

Quadro 1 - Perfil dos participantes

\begin{tabular}{|c|c|c|c|}
\hline Pseudônimo & Sexo & Idade & $\begin{array}{c}\text { Já estudou } \\
\text { inglês? Por } \\
\text { quanto tempo? }\end{array}$ \\
\hline Beatriz & Feminino & 40 anos & Não \\
\hline Cartur & Masculino & 61 anos & $\begin{array}{l}\text { Sim. Estudou } \\
\text { durante } 6 \\
\text { semestres, num } \\
\text { curso livre de } \\
\text { inglês, há vinte } \\
\text { anos atrás. }\end{array}$ \\
\hline Cecília & Feminino & 31 anos & $\begin{array}{l}\text { Sim. Estudou no } \\
\text { ensino médio. }\end{array}$ \\
\hline Eliana & Feminino & 43 anos & $\begin{array}{l}\text { Sim. Do } 7^{0} \text { ao } 9^{\circ} \\
\text { ano do ensino } \\
\text { fundamental. }\end{array}$ \\
\hline Mila & Feminino & 22 anos & $\begin{array}{l}\text { Sim. Estudou do 6ㅇ } \\
\text { ano até o fim do } \\
\text { ensino médio. } \\
\text { Também cursou } \\
\text { dois semestres em } \\
\text { um curso livre de } \\
\text { inglês. }\end{array}$ \\
\hline
\end{tabular}

Fonte: Elaboração própria

Vale salientar que dois alunos desistiram de cursar o semestre no momento em que as aulas deixaram de ocorrer de forma presencial e passaram a acontecer de forma remota por conta da pandemia da COVID-19 que assolou o Brasil e o mundo. Os alunos consentiram a participação na pesquisa, assim como a utilização dos dados obtidos através da gravação e envio de um áudio, em razão da referida pandemia. Ademais, cabe frisar que os nomes referidos no decorrer da pesquisa são fictícios visando garantir o anonimato e sigilo dos participantes.

\subsection{Instrumentos para a coleta de dados}

Os instrumentos utilizados para realizar o presente estudo foram a observação não participante com notas de campo, além do questionário BALLI adaptado, a narrativa escrita e a entrevista semiestruturada.

A observação não participante (VIEIRAABRAHÃO, 2010) e as notas de campo (TRIVIÑOS, 1987) foram utilizadas com vistas a investigar e registrar as ações dos alunos durante as atividades orais propostas nas aulas online no exato momento em que elas aconteceram. Tais informações serviram para que, juntamente aos outros instrumentos, os dados gerados fossem interpretados com ainda maior riqueza de detalhes.

Já o questionário teve como base o modelo BALLI (Beliefs About Language Learning Inventory), de Horwitz (1987), tendo sido adaptado quanto ao número de enunciados e alguns termos que foram acrescidos ou alterados.

As narrativas, que, segundo Vieira-Abrahão (2010), descrevem e relatam eventos pessoais e visam captar as histórias de discentes e docentes na tentativa de explicar mais detalhadamente as ações realizadas pelos mesmos em sala de aula, foram utilizadas nesta pesquisa. Da mesma forma, foram também empregadas para que os alunos descrevessem algumas particularidades em relação ao tema explanado na narrativa da presente pesquisa orientada pela seguinte questão: "Como tem sido o seu desenvolvimento da habilidade de produção oral nas aulas online? Conte suas experiências, emoções e expectativas".

O último instrumento utilizado foi a entrevista semiestruturada (BARCELOS, 2006; LUDKE; ANDRÉ, 1986). O uso da entrevista permitiu aos participantes da pesquisa mais um momento de relatarem suas experiências em relação ao desenvolvimento da habilidade de produção oral em aulas online e aos pesquisadores de sanar algumas dúvidas que surgiram a partir dos dados coletados através dos demais instrumentos. 


\subsection{A coleta dos dados}

A coleta dos dados através dos instrumentos supracitados ocorreu de forma virtual em razão da pandemia da COVID-19, já que o distanciamento social foi determinado para evitar a proliferação da doença, devendo as aulas, que haviam iniciado de forma presencial, continuarem a ocorrer de forma remota.

A coleta dos dados foi realizada durante os meses de junho a agosto de 2020. Num primeiro momento foram realizadas as observações e notas de campo concomitantemente. As mesmas foram realizadas nos dias 1, 8, 15 e 23 de junho, perfazendo assim um total de oito aulas observadas, já que essas são duplas. Num segundo momento foi aplicado o questionário BALLI adaptado online, que foi enviado na segunda quinzena de junho aos participantes. $\mathrm{Na}$ mesma data foi solicitado aos alunos que escrevessem uma narrativa, com a expectativa de que eles acrescentassem detalhes que não puderam ser captados através do questionário, para posterior devolução, se possível, até a primeira quinzena de julho. Por último, a entrevista foi realizada durante a primeira semana de agosto.

\subsection{Procedimento para a análise de dados}

A técnica utilizada para a interpretação dos dados gerados foi a análise de conteúdo (BARDIN, 1977). De posse das notas de campo, do questionário e da narrativa foi feita uma pré-análise dos dados antes de realizar a fase seguinte, qual seja das entrevistas semiestruturadas. As mesmas foram realizadas na primeira semana de agosto para esclarecimento de algumas informações que não ficaram claras, assim como a obtenção de novos dados atinentes ao tema da pesquisa. Conforme Barcelos (2010), as pesquisas de crenças atualmente utilizam várias fontes de coleta, - que favorece a triangulação (PRODANOV; FREITAS, 2013). Após a coleta de dados, buscamos organizá-los e construir categorias (LUDKE; ANDRÉ, 1986), cuja intenção foi identificar e interpretar a relação entre as crenças e ações dos aprendizes quanto ao próprio desenvolvimento de produção oral durante as aulas online.

\section{ANÁLISE E DISCUSSÃO DE DADOS}

\subsection{Questionário BALLI adaptado}

A partir da análise dos dados coletados através do questionário BALLI adaptado foi possível constatar que todos os cinco participantes da pesquisa concordam que as aulas online têm limitações quanto ao desenvolvimento da produção oral (2). Por essa razão, os mesmos julgam que um número maior de atividades com esse foco deveria ser proposto (5), oferecendo assim, maiores oportunidades de participação e prática (18). Apesar de todos julgarem relevante tentar usar a língua inglesa durante as aulas online, sem a preocupação de ter que falar tudo corretamente (16) ou de serem, por vezes, corrigidos pelo professor ou colegas da turma (19), dois alunos se sentem envergonhados e não confiantes para falar em inglês no decorrer das aulas online $(12,14)$. Por fim, quatro dos cinco participantes da pesquisa acreditam estar conseguindo, de alguma forma, desenvolver sua produção oral durante as aulas online (1). O mesmo quantitativo de alunos acredita que vão aprender a falar inglês praticando e, por isso, buscam aproveitar todas as oportunidades que surgem nas aulas online com essa finalidade (10), se esforçando para manter a comunicação na língua-alvo durante as aulas (7).

\subsection{Narrativa escrita e entrevista semiestruturada}

Na busca por melhor compreender e analisar os dados obtidos em relação às crenças e ações dos alunos que participaram deste trabalho, esses foram organizados e divididos em duas categorias: "Crenças e ações que comprometem o desenvolvimento da produção oral durante a aula online na visão discente" e "Crenças e ações que potencializam o desenvolvimento da produção oral durante a aula online na visão discente". 


\subsubsection{Crenças e ações que comprometem o} desenvolvimento da produção oral na visão discente

Reiterando o que já haviam respondido no questionário, quatro dos cinco alunos questionados acerca do próprio desenvolvimento da produção oral durante as aulas online relataram terem alcançado certo avanço, mas que esse ficou aquém do esperado. Os alunos tendem a comparar as aulas online com as presenciais, conforme revelado no excerto a seguir:

[1] Beatriz: Acredito que o meu desenvolvimento na habilidade de produção oral nas aulas online é bom, porém acho que nas aulas presenciais seria melhor. Em se tratando de habilidade oral, penso que 0 desenvolvimento é melhor em aula presencial, pois fica mais fácil a correção do aluno pelo professor. Sem contar os problemas de conexão que inevitavelmente ocorrem. (Narrativa)

Coadunando com a colocação anterior, seguem os comentários de outro participante:

[2] Catur: $O$ aprendizado nas aulas online com relação ao desenvolvimento de produção oral não é o mesmo das aulas presenciais, mas eu progredi. Em sala de aula há muitas maneiras de exercitar a oralidade (leitura, repetição, conversa com colegas, etc.) (Narrativa)

Nos apontamentos acima, percebemos que os alunos acreditam que conseguem desenvolver a produção oral nas aulas online e notamos, também, a crença deles em relação à maior probabilidade de se desenvolverem oralmente se tiverem mais momentos de prática, assim como receberem correções mais incisivas. Durante as observações das aulas, foi perceptível que os alunos não conseguiam interagir com os colegas e com o professor como o faziam nas aulas presenciais segundo suas próprias colocações, embora tenham ocorrido momentos de leitura em pares e interação entre os alunos e professor, principalmente através de perguntas e respostas. Oxford (1990), Marcuschi (2010) e Feijó e Mukai (2014) salientam a importância de momentos de interação quando se busca o aprimoramento da produção oral.
Reiterando o aspecto da correção acima mencionado pelos discentes, foi destacado por todos os participantes como desfavorável o fato de que, em certos momentos da aula, em que os alunos se pronunciavam oralmente, não eram corrigidos de forma individual, e no instante em que cometiam certos deslizes, acabavam ficando com dúvidas quanto à pronúncia. Durante as observações e notas de campo, percebemos que o professor optou, em várias ocasiões, por realizar as correções depois que todos os estudantes tivessem concluído suas falas. Nesse fluxo, o docente pronunciava várias palavras e os discentes repetiam em coro. Vale salientar que foram observados, também, instantes de correção individual, porém com menor incidência. Infere-se, assim, que, ao serem corrigidos, os alunos pareciam se sentir mais seguros para prosseguirem falando, conforme explicitado nas assertivas abaixo:

[3] Cecília: O professor corrige com todo mundo falando ao mesmo tempo e, às vezes, uma palavra passa despercebida. Às vezes, você não consegue entender a pronúncia direito. (Entrevista)

A fala seguinte revela que a aluna comunga o mesmo pensar:

[4] Mila: Eu sentia falta do professor tirar essas dúvidas, tipo corrigir o que a gente errou, as falas, etc. Às vezes, a gente só tem esse retorno depois da fala. (Entrevista)

Conforme se pode observar, a próxima participante acrescenta ainda o problema do áudio como mais um agravante.

[5] Eliana: A questão do áudio prejudicou um pouco. Eu não conseguia ouvir com tanta clareza quando o professor estava me corrigindo. Eu ficava sempre na dúvida se estava certo ou não. (Entrevista)

Apesar de todos enfatizarem o desejo de serem corrigidos individualmente durante as aulas online e de não se importarem com isso, as alunas Cecília e Beatriz destacaram serem muito envergonhadas e que não se sentiam confiantes para falar em inglês com os colegas e professor durante as aulas online. Sendo assim, ficavam caladas ou iniciavam uma fala, mas não davam continuidade. Conforme destacam Aragão, 
Paiva e Junior (2017), fatores como vergonha e insegurança podem gerar um bloqueio, dificultando a comunicação dos alunos.

[6] Cecília: Eu fico com vergonha de pronunciar errado. Na hora de falar falta a palavra, a pergunta, aí eu fico com vergonha e eu desisto, eu fico insegura. (Entrevista).

[7] Beatriz: Às vezes, eu falo errado e faço perguntas, com todo mundo vendo, assim dá um pouquinho de vergonha. (Entrevista)

Divergindo do que havia respondido no questionário, a aluna Mila, durante a entrevista, revelou se sentir envergonhada e não confiante para falar inglês durante as aulas online.

[8] Mila: Não aproveito todos os momentos porque eu fico envergonhada de falar errado. Ainda não me sinto confiante pra ficar falando em todos os momentos. (Entrevista)

Outro fator observado e declarado por todos os alunos é que quando se realizam atividades orais em conjunto, durante as aulas online, a produção oral fica prejudicada.

[9] Eliana: Eu acho que nessa hora do conjunto falando, todo mundo respondendo ao mesmo tempo, foi o que ficou mais prejudicado, porque tanto não dá pra ouvir o colega, como não dá para o outro te ouvir. Fica uma coisa meio bagunçada. (Entrevista)

A aluna explicita como desfavorável o fato de todos ficarem falando ao mesmo tempo. Isso aconteceu em certos momentos durante a correção de atividades de casa, por exemplo, conforme constatado durante as observações das aulas. Por vezes, algum aluno pedia que as respostas fossem repetidas por falta de compreensão. Para esclarecer certas dúvidas, em dados momentos, o professor digitava algumas respostas no chat.

Uma outra crença de dois dos cinco participantes que provavelmente tenha refletido na evolução da produção oral dos mesmos foi não terem conseguido estudar em casa, por vezes, como fizeram em semestres anteriores. Tal fato pode ter sido ocasionado, entre outros motivos, pelo momento de incertezas que vivenciamos por conta da pandemia da COVID-19, além da somatização de tarefas domésticas e/ou familiares a serem desempenhadas em face do isolamento social estabelecido, conforme demonstram os excertos a seguir:

[10] Mila: Presencialmente, eu também estudava mais inglês, eu revisava mais, fazia as atividades, igual eu falei, às vezes, eu deixava muito de fazer as atividades. A minha motivação maior é mais no presencialmente do que online. Não sei se também devido ao momento que a gente tá vivendo. (Entrevista)

[11] Beatriz: Esse semestre, assim, ficou mais complicado. O trabalho estava home office, com os meninos aqui. Depois voltei a trabalhar. Eu não estudei tanto quanto no outro semestre. (Entrevista)

Nesta seção, os discentes apresentaram algumas de suas crenças que nasceram das experiências vividas pelos mesmos no contexto de aprendizagem em que se encontram inseridos (BARCELOS, 2011; KALAJA, 1995) particularmente nesse momento em que as aulas acontecem de forma online.

4.2.2 Crenças e ações que potencializam o desenvolvimento da produção oral durante a aula online na visão discente

Apontamos, na sequência, alguns excertos que têm relação com ações realizadas pelos alunos no momento em que as aulas online acontecem e que os mesmos acreditam poder auxiliá-los na progressão oral, de algum modo. Conforme elucida Barcelos (2010), existe uma relação interativa entre crenças e ações onde tanto as ações podem ser influenciadas pelas crenças, como as crenças podem ser influenciadas pelas ações.

A aluna Mila relata utilizar o livro, como segue:

[12] Mila: Eu costumo ficar lendo o livro. Às vezes, eu fico vendo outras unidades pra pensar no que posso falar enquanto outra pessoa está falando. (Entrevista)

Já as alunas Eliana e Beatriz dizem tomar notas e anotar alguns vocábulos novos e como estes são pronunciados.

[13] Eliana: Eu já fiz algumas anotações durante a aula. Eu quis saber como é que eu falava fazer uma cirurgia, por 
exemplo, aí o professor falou a expressão que usava, aí eu anotei. (Entrevista)

[14] Beatriz: Eu escrevo em inglês. Às vezes, eu escrevo como se pronuncia. A pronúncia que eu entendo. (Entrevista)

O aluno Cartur confirmou na entrevista uma ação que realiza e que foi perceptível durante as observações das aulas, qual seja repetir o conteúdo visando a fixação.

[15] Cartur: Quando o professor pronuncia algo que eu não sei, depois que eu ouço, eu fico repetindo pra eu treinar e também faço anotações pra eu não esquecer. (Narrativa)

Um outro aspecto que aumenta a confiança para participar oralmente durante as atividades realizadas com essa finalidade nas aulas online é a revisão e estudo de conteúdo anteriormente às aulas. Os alunos Cartur e Eliana comentaram sobre isso, conforme evidenciado nos trechos abaixo:

[16] Eliana: Eu acho que todas as aulas que eu me preparei, com o conteúdo antes, foram bem melhores, mais interessantes pra mim. Eu não fiquei tão perdida. (Entrevista)

[17] Cartur: Eu me sinto à vontade na participação das aulas online, não tenho vergonha de errar, aceito sempre as correções, faço sempre as tarefas, pesquiso em outras mídias sobre o assunto tratado e, muitas vezes, me antecipo ao assunto a ser abordado. (Narrativa)

Conforme elucida Gonzáles (2008), o fato de se precisar pensar rápido para falar o que se deseja juntamente ao conhecimento limitado que os discentes têm acerca da língua pode dificultar a comunicação dos aprendizes. Na tentativa de minimizar essas dificuldades, os participantes revelaram realizar algumas ações, como as supracitadas, por acreditarem que elas podem ajudar a lembrar de vocábulos e de pronúncias no momento em que precisarem se expressar oralmente.

Embora os participantes não tenham colocado isso de forma explícita, podemos perceber que as ações a seguir são algumas das apontadas pelos discentes como prováveis colaboradoras no processo de desenvolvimento da produção oral durante as aulas online: tomar notas durante as aulas; participar das atividades orais propostas, sejam elas momentos de leitura, correção de atividades ou formulação de perguntas, etc.; revisar conteúdo estudado; questionar para tirar dúvidas durante as aulas; e se voluntariar para participar das atividades orais sem se retrair por medo ou vergonha.

Assim, salientamos algumas crenças dos discentes sobre possíveis atividades que, ao serem executadas durante as aulas online, possam possibilitar maiores chances de ação, de participação, de interação e de aprendizado, corroborando com a melhora na produção oral.

Um dos pontos destacados pelos participantes da pesquisa diz respeito à necessidade de que todos participem mais durante as atividades de leitura que são executadas durante as aulas.

[18] Cecília: Tinha que ter mais conversação, mais diálogo pra gente poder praticar mais o oral. (Entrevista)

O aluno Cartur, além de mencionar que todos precisam ser incentivados a participar, ainda sugere alguns momentos em que essa participação poderia acontecer:

[19] Cartur: Eu acho que o professor deve incentivar sempre aos alunos às leituras de textos e reprodução de diálogos até que todos tenham participado. (Narrativa)

A participante Beatriz menciona, assim como Cartur, a crença de que, durante as leituras de textos ou diálogos, os alunos possam exercitar mais a oralidade:

[20] Beatriz: Na leitura dos diálogos, eu acho que cada um tinha que ler tudo, todo o diálogo. Não só em dupla, mas trocar. Eu sou A você é B. Depois, você é A e eu sou B. (Entrevista)

A aluna Mila ainda enfatiza que os momentos de leitura eram mais intensos durante as aulas presenciais.

[21] Mila: Nas aulas presenciais a gente sempre trabalhava a leitura dos textos do livro, agora nem tanto. No online, nem tanto. (Entrevista) 
Várias sugestões de atividades que poderiam gerar maiores chances de prática oral, na visão dos alunos, foram destacadas, o que pode ser notado nos excertos abaixo:

[22] Eliana: Se o professor fizesse pequenas atividades, pequenos desafios de fala e nós déssemos o retorno na aula seguinte, acho que ajudaria um pouco. (Entrevista)

O aluno Cartur sugere atividades que revisem o conteúdo trabalhado no dia de aula e que propiciem oportunidades de prática na aula seguinte.

[23] Cartur: De acordo com cada conteúdo tratado no dia, o professor podia solicitar pequenos parágrafos pra incentivar a pesquisa, criatividade, desenvolver o vocabulário e incentivar a produção da oralidade. (Narrativa)

Por fim, convém destacar que os alunos acreditam que, durante as aulas presenciais, existem muito mais oportunidades de prática oral, pois declaram existir mais interação e mais retorno oral na maioria das atividades que são realizadas.

[24] Cecília: Na sala, a gente conversa com o colega do lado, tira alguma dúvida. No online, você fica ali num mundo mais fechado. (Entrevista)

[25] Mila: No presencial, a gente sentava, todo mundo tinha que falar, tinha que ler, discutir... (Entrevista)

[26] Eliana: A gente fazia jogos interativos durante as aulas, trabalhava em grupos, a gente trabalhava em duplas, trios. Então, isso era muito bom para o meu desenvolvimento. (Entrevista)

Conforme demonstrado nesta seção, os alunos, ao refletirem sobre suas crenças e ações e como estas podem levar ao aprimoramento da produção oral, se tornam mais conscientes de seu papel neste processo. Apesar disso, vimos que nem sempre o que os discentes dizem tem relação com aquilo que estes efetivamente fazem e vice-versa. Nessa direção, Barcelos (2010) aponta o desencontro entre crenças e ações, entre o dizer e o fazer.

\section{CONSIDERAÇÕES FINAIS}

Buscamos averiguar, com este trabalho, algumas das crenças dos discentes quanto ao próprio desenvolvimento da produção oral em um cenário totalmente atípico em que os mesmos, abruptamente, se viram inseridos num contexto de ensino remoto, por conta da pandemia da COVID-19. As aulas online se tornaram a única maneira possível e segura de prosseguir com o estudo da língua inglesa. Diante deste cenário, importa pontuar que todo esse contexto de mudanças pode ter influenciado diretamente nas crenças aqui relatadas pelos discentes. Nas palavras de Mukai (2014, p. 401), "as crenças são interativas e socialmente construídas a partir de nossas experiências anteriores e presentes, sendo ininterruptamente configuradas com base na ação, interação e adaptação dos indivíduos a seus contextos". Logo, esse conceito elucida o porquê de, em vários momentos, os alunos citarem experiências vividas durante as aulas presenciais em comparativo com as aulas online, já que os momentos de prática na língua-alvo são mais restritos na modalidade remota. Assim, Almeida Filho (2012, p. 72) destaca que "as aulas devem ser vistas como potenciais oásis de circulação de insumo (linguagem)".

No que diz respeito às crenças, conforme verificado na seção 4.2.1, de modo geral, os alunos perceberam melhora no desenvolvimento da produção oral em aulas online, mas que esse processo é inferior ao que ocorre em aulas presenciais. Nesse sentido, vimos que os participantes desta pesquisa acreditam que as seguintes atividades possam favorecer 0 desenvolvimento da produção oral: ter mais momentos de fala durante as aulas, em especial, de forma individual, recebendo as correções após seus pronunciamentos; realizar as atividades propostas para casa e rever o conteúdo estudado, o que dará mais segurança na hora que tiver que falar no momento da aula; ser estimulado a participar das atividades propostas; e diversificar mais atividades orais com vistas a incrementar a produção oral.

Fatores como vergonha, timidez e medo de errar foram salientados por três alunos como razões para silenciar por vezes durante as aulas online. 
Aragão, Paiva e Junior (2017) enfatizam o fato de que algumas emoções como inibição e vergonha podem bloquear a disposição para se comunicar em sala. Ainda, os referidos autores destacam que, ao se sentir confortável, seguro emocionalmente, aumentam-se as possibilidades da comunicação em língua estrangeira, como, por exemplo, em inglês.

No que se refere às ações, vimos que os discentes apontaram algumas das que enxergam como potencializadoras no desenvolvimento da habilidade de produção oral durante aulas online, sendo elas: tomar notas de pronúncia e vocabulário; repetir frases e palavras após correção; buscar no livro por algo que possa ajudar naquilo que se deseja falar; estudar e revisar os conteúdos trabalhados, assim como executar as atividades de casa; pesquisar de forma autônoma aquilo que possa contribuir para esclarecer dúvidas; questionar para elucidar dúvidas durante as aulas; e participar efetivamente das atividades orais propostas durante as aulas online (cf. seção 4.2.2).

Por fim, acerca da relação entre as crenças e ações dos alunos de língua inglesa quanto ao próprio desenvolvimento da produção oral em aulas online, eles creem que, ao executarem determinadas ações, terão possibilidades maiores de evoluir na produção oral durante as aulas remotas (cf. seção 4.2.2).

Nesse sentido, os participantes destacaram que se torna preciso não só maior envolvimento de sua parte nas atividades propostas durante as aulas online, bem como observam a necessidade de se levar a cabo o estudo para além do ensino remoto, o que implica em realizar revisões do material estudado e aumento da prática oral do conhecimento adquirido. Ademais, frisaram que a ampliação de atividades com foco na oralidade durante as aulas online seria um grande fator potencializador do processo de aprendizagem. Demonstrando que, por vezes, crenças e ações são discrepantes (BARCELOS, 2010), alguns alunos revelaram ter ciência do que precisa ser feito, mesmo que, em certos momentos, não o fizessem, vislumbrando um maior progresso na habilidade de produção oral.
Assim sendo, faz-se necessário que novos estudos se realizem com a perspectiva de melhor compreender o desenvolvimento oral dos alunos durante as aulas online com vistas a elencar estratégias que possibilitem uma melhor qualidade no processo de produção oral.

Ademais, cumpre destacar que, apesar dos discentes aderirem à modalidade à distância do ensino, sem alternativas momentaneamente para dar continuidade aos estudos senão por essa via, todos foram enfáticos em relatar preferência pelas aulas presenciais, especialmente pelo potencial de trocas, resolução de dúvidas e aperfeiçoamento da língua que este espaço proporciona.

\section{REFERÊNCIAS}

ALMEIDA FILHO, J. C. P. Fundamentos de abordagem e formação no ensino de PLE e de outras línguas. Campinas, SP: Pontes, 2011.

ALMEIDA FILHO, J. C. P. Quatro estações no ensino de línguas. Campinas, SP: Pontes Editores, 2012.

ARAGÃO, R. C.; PAIVA, V. L. M. O; JUNIOR, R. C. G. Emoções no desenvolvimento de habilidades orais com tecnologias digitais. Revista Calidoscópio, v. 15, n. 3, p. 557-566, 2017.

BARCELOS, A. M. F. Metodologia de pesquisa das crenças sobre aprendizagem de línguas: estado da arte. Revista Brasileira de Linguística Aplicada, Belo Horizonte, v. 1, n. 1, p. 71-92, 2001.

BARCELOS, A.M. F; VIEIRA-ABRAHÃO, M. H. (Org.). Crenças e ensino de línguas: foco no professor, no aluno e na formação de professores. Campinas, SP: Pontes Editores, 2006.

BARCELOS, A. M. F. Cognição de professores e alunos: tendências recentes na pesquisa de crenças sobre ensino e aprendizagem de línguas. In: BARCELOS, A. M. F.; VIEIRA-ABRAHÃO, M. H. (Org.). Crenças e ensino de línguas: foco no professor, no aluno e na formação de professores. Campinas, SP: 2 ed. Pontes, 2010. p. 15-41.

BARCELOS, A. M. F. "Eu não fiz cursinho de inglês": Reflexões acerca da crença no lugar ideal para 
aprender inglês no Brasil. In: BARCELOS, A. M. F. (Org.). Linguística Aplicada: reflexões sobre ensino e aprendizagem de língua materna e língua estrangeira. Campinas, SP; Pontes Editores, 2011. p. 297-318.

BARDIN, L. Análise de conteúdo. Lisboa: Edições 70, 1977.

BORTONI-RICARDO, S. M. O professor pesquisador: introdução à pesquisa qualitativa. São Paulo: Parábola Editorial, 2008.

DEWEY, J. Como pensamos: como se relaciona o pensamento reflexivo com o processo educativo: uma reexposição. Tradução Haydée de Camargo Campos. 3. ed. Companhia Editora Nacional, São Paulo, 1959. Originalmente publicado por Health Boston, 1933.

FEIJÓ, F. R.; MUKAI, Y. Crenças de alunos brasileiros (de japonês como LE) em relação à habilidade de fala em língua japonesa. Estudos Japoneses, v. 34, p. 46-70, 2014.

FLICK, U. Designing Qualitative Research. Los Angeles: Sage, 2007.

GONZÁLEZ, P. D. Destrezas receptivas y destrezas productivas en la enseñanza del español como lengua extranjera. Tenerife: Universidad de la Laguna, $2008 . \quad$ Disponível em: http://marcoele.com/monograficos/destrezas/. Acesso em: 28 jun. 2019.

HORWITZ, E. K. Surveying students' beliefs about language learning. In: WENDEN, A.; RUBIN, J. (Org.). Learner strategies in language learning. London: Prentice Hall International, 1987. p. 110-129.

HYMES, D. H. On communicative competence: In: DURANTI, A. Linguistic anthropology: a reader. New York: Wiley-Blackwell, 2001 [1971]. p. 53-73.

KALAJA, P. Student beliefs (or metacognitive knowledge) about SLA reconsidered. International Journal of Applied Linguistics, v. 5, n. 2, p. 191-204, 1995.

KALAJA, P.; BARCELOS, A. M. F.; ARO, M.; ROUHOTIE-LYTHY, M. Beliefs, Agency and Identities in Foreign Language Learning and Teaching. United Kingdom: Palgrave Macmillan, 2016.
LÜDKE, M.; ANDRÉ, M. E. D. A. Pesquisa em educação: abordagens qualitativas. São Paulo: EPU, 1986.

MARCUSCHI, L. A. Da fala para a escrita: atividades de retextualização. 10. ed. São Paulo: Cortez, 2010.

MARTINS, S. L. B.; MILL, D. Estudos científicos sobre a educação a distância no Brasil: um breve panorama. Inc. Soc., Brasília, DF, v. 10, n. 1, p. 119131, jul./dez. 2016.

MUKAI. Y. Crenças e necessidades de aprendizes de japonês como LE (língua estrangeira) a respeito da habilidade da escrita e materiais didáticos. Estudos Japoneses, São Paulo, n. 31, p. 193-219, 2011.

MUKAI, Y. Crenças e necessidades em relação à escrita em japonês: nos casos de estudantes universitários brasileiros e portugueses. Linguagem \& Ensino, Pelotas, v. 17, n. 2, p. 391-440, 2014.

OXFORD, R. L. Language Learning Strategies: what an every teacher should know. Boston: Heinle; Heinle Publishers, 1990.

PAIVA, V. L. M. O. Tecnologias digitais para o desenvolvimento de habilidades orais em inglês. D.E.L.T.A., v. 34, n. 4, p.1319-1351, 2018.

PAJARES, F. M. Teachers' beliefs and educational research: Cleaning up a messy construct. Review of Educational Research, v. 62, n. 3, p. 307332, 1992.

PRODANOV, C. C.; FREITAS, E. C. Metodologia do trabalho científico [curso eletrônico]: métodos e técnicas da pesquisa e do trabalho acadêmico. 2. ed. Novo Hamburgo: Feevale, 2013.

RILEY, $P$. The guru and the conjurer: aspects of counselling for self access. In: BENSON, P.; VOLLER, P. (Org.). Autonomy and independence in language learning. New York: Longman, 1997. p. 114-131.

SANTOS, G. L. Ensinar e aprender no meio virtual: rompendo paradigmas. Educação e Pesquisa, São Paulo, v. 37, n. 2, p. 307-320, mai./ago. 2011.

SANTOS, J. C.; BARCELLOS, A. M. F. "Não sei de onde vem essa timidez, talvez um medo de parecer ridículo": um estudo sobre a timidez e a produção oral 
de alunos de inglês. Horizontes de Linguística Aplicada, Brasília, ano 17, n. 2, p. 15-38, 2018.

STAKE, R. E. Qualitative case studies. In: DENZIN, N. K.; LINCOLN, Y. S. (Org.). The Sage handbook of qualitative research. 3. ed. Sage Publications, 2005. p. 443-446.

TRIVIÑOS, A. N. S. Introdução à pesquisa em ciências sociais: a pesquisa qualitativa em educação. São Paulo: Atlas, 1987.

VASCONCELLOS, L. F. Crenças sobre as dificuldades dos alunos no aprendizado de japonês como língua estrangeira. 2020. $67 \mathrm{f}$. Trabalho do Programa de Iniciação Científica (ProlC), Instituto de Letras, Universidade de Brasília, Brasília, 2020.

VIEIRA-ABRAHÃO, M. H. Metodologia na investigação das crenças. In: VIEIRA-ABRAHÃO, M. H; BARCELOS, A. M. F (Org.). Crenças e ensino de línguas: foco, no aluno e na formação de professores no professor. 2. ed. Campinas, SP: Pontes, 2010. p. 219-231.

YIN, R. K. Estudo de caso: planejamento e métodos. Tradução Daniel Grassi. 2. ed. Porto Alegre: Bookman, 2001.

BEZERRA DA SILVA FERNANDES, Mônica; MUKAI, Yûki. Crenças e ações dos discentes quanto ao desenvolvimento da habilidade de produção oral durante aulas online na pandemia da COVID-19. Signo, Santa Cruz do Sul, v. 46, n. 85, p. 35-47, jan. 2021. ISSN 1982-2014. Disponível em: <https://online.unisc.br/seer/index.php/signo/article/view/15651>. doi:https://doi.org/10.17058/signo.v46i85.15651. 